\title{
The emerging research on indigenous management in Asia
}

\author{
Peter Ping $\mathrm{Li}^{1,2} \cdot$ Tomoki Sekiguchi ${ }^{3} \cdot$ Kevin $\mathrm{Zhou}^{4}$
}

Published online: 10 August 2016

(C) Springer Science+Business Media New York 2016

It is our great pleasure to introduce the Special Issue of the Asia Pacific Journal Management with the focus on the theme of indigenous management research in Asia. This introduction is organized into three parts, with the first part covering the background and review process of the Special Issue; the second part covering the specific contents of the ten articles included in the Special Issue, and the third part covering the critical implications of the Special Issue.

\section{The background and review process of the Special Issue}

It has been long recognized that indigenous research should be helpful, if not essential, for an adequate understanding of any local phenomenon or issue. The indigenous approach is consistent with the repeated calls for contextualizing organization research. Paradoxically, globalization gives rise to a greater need for indigenous research so as to adequately analyze each unique local context in which domestic and multinational firms operate. In particular, given the fact that most of extant theories of management and organization are built upon the cultural values and empirical evidence in the West, it is imperative to conduct indigenous research to likely revise and modify, potentially supplement and enrich, or even supersede and replace the Western theories.

In the context of Asian region, with the region's long and complex histories as well as its rich and diverse cultures, there are many interesting phenomena or issues that are potentially indigenous to Asia and distinctive from those in the West, including the

Peter Ping Li

ppl.int@cbs.dk

1 Xian Jiaotong-Liverpool University, Suzhou, China

2 Copenhagen Business School, Frederiksberg, Denmark

3 Osaka University, Suita, Japan

4 University of Hong Kong, Pok Fu Lam, Hong Kong 
philosophical, religious, economic, political, social, and intellectual traditions that often shape the organizational patterns and managerial styles in the Asian region. Understanding these phenomena or issues and their influence on the society-level, firm-level, team-level, and individual-level behaviors will benefit from, if not require, the input of the indigenous approach.

However, the challenges of indigenous research are enormous. First, there is little consensus regarding what indigenous research is. Some argue that it qualifies as indigenous research if one studies an indigenous topic, even if Western theories are adopted; others maintain that indigenous research requires certain contextual factors that are indigenous but that the dominant theoretical framework can be borrowed from the West; still others posit that only when an indigenously developed theory is adopted or developed can the research be qualified as indigenous. Second, the above controversy is related to the vision and goal of indigenous research. Is it intended to verify the extant Western theories? Is it designed to modify the extant Western theories? Is it sought to develop new theories with broad geocentric implications to supplement or even supersede the extant Western theories? Third, the above controversies extend to methodological considerations. Do we simply adopt the prevailing methods in the West? Should we develop indigenous methods for indigenous research? We need to address these questions and challenges.

It is worth noting that $A P J M$ enjoys the leading position in the indigenous research movement in Asia with almost all the major articles to call for the indigenous research in Asia being published in APJM (e.g., Chen, 2002; Fang, 2010; Li, 2012a; Meyer, 2006; Tsui, 2004; White, 2002), so we have the obligation to answer the calls for the indigenous research in Asia. For that purpose, this Special Issue of APJM has sought to shed light on the above challenges and questions. In this Special Issue, we have tried to explore various approaches and diverse topics concerning indigenous research in Asia.

Specifically, we have defined indigenous research in a broad sense to encompass the context- sensitive and context-specific approaches to a uniquely local phenomenon or issue in Asia, which may have global implications. In other words, if a study is deeply embedded in the Asian context with strong Asian relevance, it can be qualified as an indigenous research in Asia. However, we have encouraged those studies that adopt a uniquely Asian perspective in contrast to the mainstream perspectives in the West. Hence, we have sought those manuscripts that report empirical research addressing those phenomena or issues unique to Asia, and particularly those phenomena or issues that defy predictions or explanations by the extant theories derived from the Western contexts. We have also welcomed theory-building studies that introduce novel theoretical insights, from a uniquely Asian perspective, into local phenomena or issues that may or may not be unique to Asia. Both qualitative and quantitative research methods have been equally emphasized. In essence, we have encouraged creative research designs solidly grounded in the context of Asian cultural traditions. In other words, we have specifically invited those submissions that would incorporate or address, but not limited to, the following three approaches:

(1) Indigenization-from-within approach: Contextualizing research and developing the indigenous constructs and models that are distinctive from the prevailing Western ones.

(2) Cross-indigenization geocentric approach: Supplementing and enriching the Western constructs and models with the indigenous constructs and models, with the purpose of developing geocentric (i.e., both emic/local and etic/universal) theories. 
(3) Unique methodological issues confronting the indigenous research: Developing and illustrating uniquely indigenous research methods for conducting indigenous research.

Largely due to the pended need for a good outlet for publishing the indigenous research, our Special Issue has attracted a large number of submissions, with a total of 123 initial submissions right after the deadline of submission on September 1, 2014. However, the majority of those submissions were desk rejected (up to 97 submissions with a desk-rejection rate of close to $80 \%$ ) simply because they did not qualify as the indigenous research in Asia, that is, encompassing the context-sensitive and contextspecific approaches to a uniquely local phenomenon in Asia, thus resulting in only 26 submissions being sent out for review. Finally, ten submissions have been finally accepted for publication in the Special Issue (with an acceptance rate of about 8\%).

The geographical scope of all the submissions to the Special Issue covers all areas across Asia, including East Asia, Southeast Asia, South Asia, and Middle East, with the surprising exception of Japan. The ten articles in the Special Issue cover three countries (one article covering both China and South Korea): China (seven articles), India (one article), and South Korea (three articles).

\section{The specific contents of the ten articles in the Special Issue}

As the final result of our review process, we have included ten articles in the Special Issue. These ten articles fall into the above two broad categories: (1) the first group of four articles focusing on the most conspicuous local phenomenon or issue in Asia (i.e., informal relationships), and (2) the second group of six articles focusing on the inherent links between other local phenomena or issues (e.g., leadership, ethics, and cognitive mode in terms of the way of thinking) and the local cultural traditions or perspectives in Asia.

The specific contents of the first group with four articles are concerned with the informal ties as the most conspicuous local phenomenon or issue in Asia (especially in the context of East Asia, such as guanxi in China and yongo in South Korea). This set of four articles point out two salient features of the informal ties in Asia. First, the informal ties in Asia persist over time, so they seem to be rooted more in the strength of cultural traditions in Asia, rather than in the weakness of formal institutions there. In that sense, informal ties in Asia would not disappear in the foreseeable future. Second, the informal ties in Asia do not exist in a single homogenous form. On the contrary, they appear to take diverse forms despite their shared features, such as the major distinctions between guanxi in China and yongo in South Korea.

Entitled "Same but different? Similarities and fundamental differences of informal social networks in China (guanxi) and Korea (yongo)" and written by Sven Horak and Markus Taube (2016), the first article focuses on the similarities and distinctive differences between informal social networks in China (guanxi) and Korea (yongo). Within an analytical framework derived from social capital and institutional theory, the structural forms and characteristics of both network forms are compared. Although we observe some similarities, surprisingly, the two networks show several fundamental differences. Both are society-spanning constructs, developed and maintained by 
reciprocal action that creates trust and trustworthiness, and serves as a major factor in network cohesion. Both networks are relatively closed or inaccessible to outsiders, with insiders able to connect other insiders to each other (i.e., internal bridging of structural holes). However, guanxi can be framed as being utilitarian (purpose-based), while yongo in principle describes cause-based ties. Further, guanxi networks are somewhat accessible to outsiders and draw on a diverse base of ties; yongo networks are predefined, partly by birth, and are hence homogeneous and highly exclusive. Guanxi networks can benefit from spillover effects through bridging different networks; Yongo networks often cannot, as there is antipathy, competition, and potentially hostility between certain types of networks. The results add knowledge to social network theory in general and in particular on informal social networks in East Asia.

Entitled "Why do Chinese employees build supervisor-subordinate guanxi? A motivational analysis" and written by Long Zhang, Yulin Deng, Xin Zhang, and Enhua $\mathrm{Hu}$ (2016), the second article focuses on the informal links between supervisors and their subordinates. Supervisor-subordinate guanxi is an informal leader-member relationship that is of utmost importance in Chinese organizations. This paper explores Chinese employees' motives for building supervisor-subordinate guanxi through two studies. Study 1 develops an indigenous scale of motives for supervisor-subordinate guanxi. Four motive types (i.e., career advancement, team concern, personal life, and impression management) are identified, and the scale's convergent and discriminant validity is established. Study 2 examines the predictive power of these motive types. The results indicate that they, as a whole, account for unique variances in supervisorsubordinate guanxi. Furthermore, as single motive types, they have unequal impacts on this relationship and its dimensions. This research enhances understanding of what underlies supervisor-subordinate guanxi from a motivational perspective and has implications for Chinese indigenous research of guanxi.

Entitled "Guanxi circle and organizational citizenship behavior: Context of a Chinese workplace" and written by Jar-Der Luo, Meng-Yu Cheng, and Tian Zhang (2016), the third article focuses on the structural issue of guanxi circle as a special type of guanxi network. According to leader-member exchange theory, good vertical working relations encourage organizational citizenship behavior that benefits organization. But how does supervisor-subordinate guanxi influence employees' extra-role behaviors in relation to organizational interests? To answer this question, this paper examines a particular structural phenomenon in the context of the Chinese workplace. Guanxi circles (the phenomenon under investigation) are ego-centered guanxi networks with a powerful person at the center. Although a circle leader and his or her group members exchange favors for private goals, they need to actively balance their own interests with the interests of people/groups outside the guanxi circle; so as to maintain a harmonious relationship with the larger network. For this reason, extra-role performance benefiting the larger network is encouraged in the management of a guanxi circle. By studying survey data from China, the authors demonstrate how a wide variety of circle roles facilitate extra-role performance, and ultimately benefit the organization as a whole. Circle bridges have higher OCB-O than peripheral members of a circle, who in turn have higher OCB-O than core members of the same circle.

Entitled "Persistence of informal social networks in East Asia: Evidence from South Korea" and written by Sven Horak and Andreas Klein (2016), the fourth article focuses on the nature and influence of informal social networks in South Korea (yongo) by 
analyzing trust levels and network cohesion. Predominantly based on studies on Chinese guanxi, it is widely believed that the further a nation develops stable formal institutions the more the influence of informal relations decreases. Given South Korea's position as a strong economic powerhouse with established rule of law and democratic institutions, the influence of yongo should play an insignificant role today. The authors find significant evidence that network cohesion of yongo is still strong in South Korea, despite its economic rise. Contrary to expectation, the authors observe a higher than expected degree of general trust and a continuous commitment to yongo ties at the same time. These findings document recent changes in South Korea such as the beginning of its multicultural opening, whereas informal yongo ties, characterized by emotional interpersonal bonds, still remain pronounced. Foremost, the authors recommend current beliefs about the correlation of institutional development and decreasing informal transactions to be reconsidered. The authors propose further studies to better understand how informal social networks evolve over time.

In sum, the first set of four articles point out two salient features of the informal ties in Asia in terms of the persistence of informal ties in Asia as well as the salient distinctions between the specific forms of informal ties in Asia.

Further, the specific contents of the second group with six articles are concerned with the inherent links between other local phenomena or issues (e.g., leadership, ethics, and cognitive mode in terms of the way of thinking) and the local cultural traditions in Asia, especially the applications of the local cultural traditions to various business-related phenomena or issues. This set of six articles point out two salient perspectives rooted in the local cultural traditions in Asia. First, the unique perspective of Yin-Yang balancing is specifically positioned to manage all paradoxes, which are increasingly recognized as the most challenging issues in the field of organizational management. In this sense, the Asian perspective of Yin-Yang balancing has the best potential to remedy the limitations of the logical systems in the West (i.e., the Aristotelian "either/or" logic and the Hegelian "both/and" logic) for paradoxes. Second, the ethical perspectives derived from Confucianism and religions are also tied to many managerial issues in the context of Asia with potential global implications.

Entitled "Tian-ren-he-yi strategy: An Eastern perspective" and written by Mike W. Peng, Yuan Li, and Longwei Tian (2016), the first article in the second group focuses on the application of a specific perspective rooted in the traditional Chinese philosophies to the issue of business-environment dilemma. Research on the businessenvironment dilemma has traditionally focused on strategies based on isolated, either/ or mindsets, such as economically-oriented or environmentally-oriented strategies. Drawing on the cultural, philosophical, and intellectual traditions of China, the authors sketch the contours of a new holism-based strategic mindset, which results in a tianren-he-yi strategy. As an Eastern perspective, tian-ren-he-yi (天人合一) means "nature and mankind combined as one" or "nature-human harmony." The authors leverage both qualitative and quantitative investigations to first identify the underlying mechanisms connecting tian-ren-he-yi strategy and firm performance, and then to compare the performance-enhancing potential of tian-ren-he-yi strategy with the two strategies based on the isolated mindset. Their analysis shows that when managing the business-environment dilemma, tian-ren-he-yi strategy has stronger performanceenhancing potential than either economically-oriented or environmentallyoriented strategies. 
Entitled "YinYang bipolar dynamic organizational modeling for equilibrium-based decision analysis: Logical transformation of an indigenous philosophy to a global science" and written by Wen-Ran Zhang, Karl Peace, and Hyo-Joo Han (2016), the second article focuses on the scientific basis of Chinese Yin-Yang philosophy. While it is recognized that indigenous research on China is helpful if not essential, the essence of YinYang has never been made clear in logical forms. While indigenous research should be guided by a philosophy, it was widely believed that without a unique logical system China only had culture but no philosophy. Now, worldwide indigenous research on China is faced with tremendous difficulties due to the lack of principles, academic disciplines, and a scientific common ground even though the Chinese YinYang has been widely influential. Consequently, a unique formal logical foundation is imperative for a logical reincarnation of Chinese philosophy. It is shown in this work that a formal equilibriumbased and harmony-centered YinYang bipolar dynamic logic (BDL) can fill the gap. Based on BDL, bipolar dynamic organizational modeling (BDOM) is proposed for equilibrium-based decision analysis (EBDA). It is shown that BDOM/EBDA methodologies can integrate case study methods and grounded theory together into a holistic and dynamic management paradigm for global regulation. The three philosophies of metaphysics, dialectics, and the Dao of YinYang are formally classified and distinguished. It is argued that with BDL YinYang is elevated to a formal logical system, and indigenous research on China is positioned in the context of a global science with a common philosophical ground of equilibrium, complementarity, and harmony. It is concluded that, with YinYang as a philosophical guiding light, not only is bipolar dynamic equilibriumbased indigenous research helpful but also fundamental and essential.

Entitled "Top executive leaders' compassionate actions: An integrative framework of compassion incorporating a Confucian perspective" and written by Hongguo Wei, Yunxia Zhu, and Shaobing Li (2016), the third article focuses on the development of a theoretical framework for understanding compassion. It contributes to the research of compassion from an indigenous theory perspective to complement the Western theory of this important topic. The authors do this by adopting self-cultivation, a Confucian indigenous theoretical perspective based on xin (mind-heart) to guide their grounded study and thus develop an integrative framework. With an analysis based on extensive interviews with top executive leaders in Chinese enterprises, the authors show that (1) integrating compassion and self-cultivation enriches our understanding of the moral growth of compassion; (2) compassion affects performance outcomes at the individual, relational and organizational levels, and (3) self-cultivation and compassion have an ultimate interaction effect on organizational performance outcomes.

Entitled "Perceived managerial and leadership effectiveness in a Korean context: An indigenous qualitative study" and written by Dae Seok Chai, Shinhee Jeong, Junhee Kim, Sewon Kim, and Robert Hamlin (2016), the fourth article focuses on the Confucian influence on the leadership style among Korean firms. The purpose of this exploratory qualitative study is to identify what Korean managers and non-managerial employees perceive to be effective or ineffective managerial behaviors from an emic perspective. Critical incident technique was used to collect concrete examples from 45 managers and non-managerial employees of observed managerial behaviors that they perceived as effective and ineffective. While the emphasis was given to both effective and ineffective managerial behaviors with a holistic approach, 38 distinctive behavioral categories of effective and ineffective managerial behavior were derived. Furthermore, 
the seven overarching indigenous themes of Korean managerial behavior emerged, offering an insightful, contextually relevant, and richly described understanding of perceived managerial and leadership effectiveness in a Korean context. The authors identified and described several Korean cultural concepts embedded in the indigenous themes, which may confirm implicit leadership theory. After discussing the theoretical and practical implications of their findings, the authors provide the limitations of this study and several directions for future research. As one of the first attempts at identifying indigenous Korean managerial and leadership effectiveness, this study could become a cornerstone for advanced indigenous empirical studies and a catalyst for dialogue related to indigenous managerial and leadership research, especially in Korean and other East Asian contexts.

Entitled "The contextualization and de-contextualization of Confucian morality: Making Confucianism relevant to China's contemporary challenges in business ethics" and written by Tony Qian Liu and Bruce Stening (2016), the fifth article focuses on how to frame Confucianism in the modern context. In response to serious ethical problems in China, Confucianism is being invoked as a possible solution. The authors argue that to apply Confucianism as a useful resource for developing business ethics in China, two processes are needed - contextualization and de-contextualization. The paper puts Confucian moral concepts back into their original context for more accurate interpretation and better understanding, and then discusses the adjustments that need to be made before applying them in today's business environment. Five important Confucian conceptsren, $y i, l i, z h i$, and xin - are examined and two suggestions are provided for the effective application of Confucian morality in business ethics in present-day China: the introduction of codified ethics and a clear focus on individual behavior.

Entitled "Religiosity, spirituality and ethical decision-making: Perspectives from executives in Indian multinational enterprises" and written by Subramaniam Ananthram and Christopher Chan (2016), the sixth and last article in the second group focuses on the salient role of religion on business decision-making, especially in the context of India. Through a semi-structured interview with 40 senior executives from Indian multinational enterprises (MNEs), the authors use virtue ethics theory to examine the types of virtues that are promulgated by religiosity and spirituality in shaping ethical behavior. The responses were coded in NVivo and the themes and concepts were organized into four categories (e.g., environmental context, individual religious virtues, individual non-religious spiritual virtues, and organizational ethical virtues). These categories contributed to ethical decision-making. The findings suggest that it is critical to understand ethical decision-making by identifying virtues that are important in religious, spiritual and humanistic contexts in countries such as India, which are religiously and spiritually diverse. The study findings assist in the development of a framework of ethical decision-making that can be used for further empirical testing across both non-Western and Western contexts in multi-faith populations. Several theoretical, practical, and methodological contributions are presented along with suggestions for future research.

In sum, the second set of six articles point out two salient perspectives rooted in the local cultural traditions in Asia. First, the unique perspective of Yin-Yang balancing is specifically positioned to manage all paradoxes. Second, the ethical perspectives derived from Confucianism and Asian religions are relevant to various managerial issues in the context of Asia with potential global implications. 


\section{The critical implications of the Special Issue}

\section{The key theoretical implications}

As reflected in the four articles (out of the total collection of ten articles in our Special Issue), the phenomenon or issue of informal network in Asia (e.g., guanxi in China, and yongo in South Korea) is now widely known among the management researchers cross the world. We are more convinced by the four articles in our Special Issue that this line of research will continue to flourish, so we can learn a lot by developing more sophisticated theories about the informal networks in Asia. It is worth noting that the next Special Issue of APJM, entitled "Informal social networks in East Asia," will be devoted to this specific topical domain. There appear to be both fundamental similarities and distinctions between the informal social networks in East Asia as a region with many shared cultural traditions. This is especially true for those among China, Japan, and South Korea as the top three economies in this region so that we can develop an Asian theory of informal social networks in contrast and also as supplement to the Western theory of formal relationships $(\mathrm{Li}, 2007 \mathrm{a}, \mathrm{b})$. This reflects the so-called "indigenization-from-within approach," which focuses on contextualizing research and developing the indigenous constructs and models that are distinctive from the prevailing Western ones.

We argue that developing a theory of informal social networks based on guanxi alone is insufficient. We need to expand the research on informal social networks to other major countries in East Asia, especially Japan and South Korea. For instance, the three countries share the same traditional notion of informal social network, termed "renmai" in Chinese, "jin myaku" in Japanese, and "inmaek" in Korean, all being based on the same Chinese characters of “人脉." Is “jin myaku” in Japan the same as or distinctive from "renmai" in China or "inmaek" in South Korea? Why are the informal social networks in East Asia similar or distinctive? Such questions remain to be answered. Hence, there is a major research gap concerning the features, antecedents, consequences, and also persistence, of informal social networks in East Asia, especially in the context of the link between formal and informal institutions in China, Japan, and South Korea. Due to the above reasons, the Special Issue on the informal social networks in East Asia attempts to contribute to currently ongoing debates by aiming to shed light on the following fundamental questions:

- What are the major similarities and distinctions between the informal social networks in East Asia in general, and China, Japan, and South Korea in particular?

- What are the similarities and distinctions between the informal social networks in East Asia and the concept of social capital as conceptualized in the West?

- Would informal social networks persist or disappear when formal institutions are more established in the later stages of societal development?

Further, as reflected in the six articles, the perspectives deriving from the Eastern philosophies and religions, such as Confucianism and Taoism (with the cognitive frame of Yin-Yang balancing as its epistemology), are quintessential in shaping indigenous phenomena or issues in Asia. Such culturally rooted perspectives bear both the salient implications for the indigenous management theories in the context of Asia (i.e., the 
emic approach) and for the global management theories across the diverse contexts of the world (i.e., the etic approach). While some of the articles in this set still apply the so-called "indigenization-from-within approach," other articles (e.g., the article on tianren-he-yi strategy as well as the article on Yin-Yang perspective) adopt the so-called "cross-indigenization geocentric approach," which focuses on supplementing and enriching the Western constructs and models with the indigenous constructs and models, with the purpose of developing geocentric (i.e., both emic/local and etic/universal) theories. In this sense, the "cross-indigenization geocentric approach" (i.e., starting from the local perspectives applicable to both local and global phenomena) seems more effective than the "indigenization-from-within approach" (i.e., starting from the local phenomena) in terms of developing more novel theories applicable to both local and global phenomena.

For example, the cognitive frame of Yin-Yang balancing bears both indigenous (emic) and global (etic) implications for management research and practice. As the underlying core of Eastern philosophy of wisdom, Yin-Yang balancing has inherent geocentric implications (Li, 2012a, 2016; Lin, Lu, Li, \& Liu, 2015). This system can operate in the Western context, as shown in the case of Lego, a Danish toy-maker, that adopts eleven paradoxical principles, similar to the practices in China, as found in a recent study (Zhang, Waldman, Han, \& Li, 2015). Across the broad domain of management, more Western scholars explicitly evoke the notion of Yin-Yang balancing to explore how to manage various paradoxes (see Schad, Lewis, Raisch, \& Smith, 2016 for the most recent review). The cognitive system of Yin-Yang balancing holds potential as a major contribution from the East to the West in the context of the East meeting the West as equal partners (Chen \& Miller, 2011). As each epistemological system has distinctive strengths and weaknesses, there is need for an asymmetrical balance between the two partners in each specific domain (e.g. the either/or logic as the dominant in the domain of largely simple and certain, thus non-paradoxical, analysis; the either/and logic as the dominant in the domain of largely complex and uncertain, thus paradoxical synthesis) in the context of globalization as the etic-emic balancing. Given the growing recognition that indigenous research is necessary for a global body of wisdom and knowledge (Li, 2012a, b, c), we need to apply the Eastern philosophy of wisdom (with Yin-Yang balancing as the epistemological component) in addition to the Western philosophy of knowledge (with the either/or logic as the epistemological component). The major achievement of $\mathrm{Dr}$. $\mathrm{Wu}$ Wen-Tsun in the field of mathematics is a good example of integrating Chinese traditional mathematics with the modern mathematics in the West (Hudecek, 2014). The 2015 Nobel Prize winner, Madam Youyou Tu, is another example of integrating the East and the West in the area of medicine. More achievements in the future can be expected from the West-meetingEast trend, and, as scholars, we have an obligation to facilitate this effort.

In general, the lower-order value of Yin-Yang balancing is its ability to explain holistic, dynamic, and duality-rooted issues, while the higher-order value is its ability to absorb the "either/or" logic, and allow it (other systems) to primarily manage fragmented, static, and consistent issues. Perhaps it is not an exaggeration to say that the cognitive system of Yin-Yang balancing can yet present the most valuable tool of paradox management. However, it is unrealistic to expect that Yin-Yang balancing will be perfect, and our current knowledge about the system remains immature. Our future challenge is to enhance and integrate it with other systems into a geocentric meta- 
system. The unique article on Yin-Yang system in this Special Issue is taking the necessary steps in the right direction.

Finally, we want to comment on the methodological issues confronting the indigenous research. It is encouraging to note that the majority of the articles in this Special Issue adopt the qualitative and inductive methods to generate novel theories or frameworks. This is natural considering the fact that the local phenomena are under-studied and poorly understood, so diverse qualitative methods are necessary (Li, 2012a; Li, Leung, Chen, \& Luo, 2012). One of the weaknesses of this Special Issue is the absence of any article focusing on the methodological issues of indigenous research. However, there are a few studies in the literature that are directly related to the methodological challenges in the indigenous research, such as the recently proposed Yin-Yang method of case study (Li, 2012c) and meta-case-study method (Li \& Zhang, 2016).

\section{The key practical implications}

All the articles in this Special Issue have some practical implications for both Western and Eastern managers. For the Western managers, these studies help them understand the local practices and local perspectives more adequately, especially the insights into the local phenomena from the local perspectives. For the Eastern managers, these studies help them explicitly understand their own management practices, which are often engaged rather unconsciously. With such understanding, the Eastern managers can be more proactive in the local practices as well as more explicit in explaining the rationales behind their local practices to non-Asian managers, which is often necessary in the context of international business.

\section{Future research directions}

As stated earlier, future research should pursue the "cross-indigenization geocentric approach" by developing more geocentric theories (e.g., Jukka, Blomqvist, Li, \& Gan, 2016; Li, 2007a, b, 2008, 2016). However, we must remind everyone that the "indigenization-from-within approach" is still necessary to develop relevant indigenous theories before we can effectively engage in "cross-indigenization geocentric approach" to developing geocentric theories (e.g., Li, 2006, 2014; Lin et al., 2015). Further, the quantitative methods and mixed methods could be used in the future to test the validity of those indigenous theories that are newly developed in the qualitative studies. For the indigenous research in particular and geocentric research in general, the newly proposed qualitative methods of Yin-Yang method of case study (Li, 2012c) and meta-case-study method (Li \& Zhang, 2016) could be helpful.

Finally, there are many other indigenous phenomena that are not included in the current Special Issue. For example, what remains relatively weak is the issue of how to apply the outcomes of the indigenous studies in the Special Issue to the management practices in other parts of the world. Much more research is needed in this area. Also, this Special Issue only covers three countries in Asia (i.e., China, Korea, and India), so we still know little about the indigenous phenomena in other Asian countries, which deserve more attention in the future. 


\section{References}

Ananthram, S., \& Chan, C. 2016. Religiosity, spirituality and ethical decision-making: Perspectives from executives in Indian multinational enterprises. Asia Pacific Journal of Management (this issue).

Chai, D. S., Jeong, S., Kim, J., Kim, S., \& Hamlin, R. G. 2016. Perceived managerial and leadership effectiveness in a Korean context: An indigenous qualitative study. Asia Pacific Journal of Management (this issue).

Chen, M. J. 2002. Transcending paradox: The Chinese "middle way" perspective. Asia Pacific Journal of Management, 19(2-3): 179-199.

Chen, M.-J., \& Miller, D. 2011. The relational perspective as a business mindset: Managerial implications for East and West. Academy of Management Perspective, 25(3): 6-18.

Fang, T. 2010. Asian management research needs more self-confidence: Reflection on Hofstede (2007) and beyond. Asia Pacific Journal of Management, 27(1): 155-170.

Horak, S., \& Klein, A. 2016. Persistence of informal social networks in East Asia: Evidence from South Korea. Asia Pacific Journal of Management (this issue).

Horak, S., \& Taube, M. 2016. Same but different? Similarities and fundamental differences of informal social networks in China (guanxi) and Korea (yongo). Asia Pacific Journal of Management (this issue).

Hudecek, J. 2014. Reviving ancient Chinese mathematics: Mathematics, history and politics in the work of Wu Wen-Tsun. London: Routledge.

Jukka, M., Blomqvist, K., Li, P. P., \& Gan, C-M. 2016. Trust-distrust balance: Trust ambivalence in SinoWestern B2B relationships. Cross Cultural \& Strategic Management (in press).

Li, P. P. 2006. Guanxi as the Chinese norm for personalized social capital: Toward an integrated duality framework of informal exchange. In H. W. Yeung (Ed.). Handbook of research on Asian busines, Ch. 4: 62-83. London: Edward Elgar.

Li, P. P. 2007a. Toward an interdisciplinary conceptualization of trust: A typological approach. Management and Organization Review, 3(3): 421-445.

Li, P. P. 2007b. Social tie, social capital, and social behavior: Toward an integrated framework of organized exchange. Asia Pacific Journal of Management, 24(3): 227-246.

Li, P. P. 2008. Toward a geocentric framework of trust: An application to organizational trust. Management and Organization Review, 4(3): 413-439.

Li, P. P. 2012a. Toward an integrative framework of indigenous research: The geocentric implications of YinYang balance. Asia Pacific Journal of Management, 29(4): 849-872.

Li, P. P. 2012b. Exploring the unique roles of trust and play in private creativity: From the complexityambiguity-metaphor to the trust-play-creativity link. Journal of Trust Research, 2(1): 71-97.

Li, P. P. 2012c. Toward research-practice balancing in management: The Yin-Yang method for open-ended and open-minded research. In C. L. Wang, D. J. Ketchen, \& D. D. Bergh (Eds.). Research methodology in strategy and management, Vol. 8, Ch. 4: 91-141. Emerald Group Publishing.

Li, P. P. 2014. The unique value of Yin-Yang balancing: A critical response. Management and Organizational Review, 10(2): 321-332.

Li, P. P. 2016. The global implications of the indigenous epistemological system from the East: How to apply Yin-Yang balancing to paradox management. Cross Cultural \& Strategic Management, 23(1): 42-77.

Li, P. P., Leung, K., Chen, C. C., \& Luo, J.-D. 2012. Indigenous research on Chinese management: What and how. Management and Organization Review, 8(1): 7-24.

Li, P. P., \& Zhang, Z. 2016. The best practices in the domain of case study: The meta-case study approach to the award-winning case study articles in the top-tier journals. In P. P. Li \& Y.-F. Cao (Eds.). A revisit to the theories and practices of case study. Beijing: Peking University Press (in Chinese).

Lin, D.-M., Lu, J.-Y., Li, P. P., \& Liu, X.-H. 2015. Balancing formality and informality in business exchanges as a duality: a comparative case study of returnee and local entrepreneurs in China. Management and Organization Review, 11(2): 315-342.

Liu, T. Q., \& Stening, B. W. 2016. The contextualization and de-contextualization of Confucian morality: Making Confucianism relevant to China's contemporary challenges in business ethics. Asia Pacific Journal of Management (this issue).

Luo, J.-D., Cheng, M.-Y., \& Zhang, T. 2016. Guanxi circle and organizational citizenship behavior: Context of a Chinese workplace. Asia Pacific Journal of Management (this issue).

Meyer, K. E. 2006. Asian management research needs more self-confidence. Asia Pacific Journal of Management, 23(2): 119-137.

Peng, M. W., Li, Y., \& Tian, L. 2016. Tian-ren-he-yi strategy: An Eastern perspective. Asia Pacific Journal of Management (this issue). 
Schad, J., Lewis, M. W., Raisch, S., \& Smith, W. K. 2016. Paradox research in management science: Looking back to move forward. Academy of Management Annals (in press).

Tsui, A. S. 2004. Contributing to global management knowledge: A case for high quality indigenous research. Asia Pacific Journal of Management, 21(4): 491-513.

Wei, H., Zhu, Y., \& Li, S. 2016. Top executive leaders' compassionate actions: An integrative framework of compassion incorporating a Confucian perspective. Asia Pacific Journal of Management (this issue).

White, S. 2002. Rigor and relevance in Asian management research: Where are we and where can we go?. Asia Pacific Journal of Management, 19(2-3): 287-352.

Zhang, L., Deng, Y., Zhang, X., \& Hu, E. 2016. Why do Chinese employees build supervisor-subordinate guanxi? A motivational analysis. Asia Pacific Journal of Management (this issue).

Zhang, W.-R., Peace, K. E., \& Han, H.-J. 2016. YinYang bipolar dynamic organizational modeling for equilibriumbased decision analysis: Logical transformation of an indigenous philosophy to a global science. Asia Pacific Journal of Management (this issue).

Zhang, Y., Waldman, D., Han, Y. L., \& Li, X. B. 2015. Paradoxical leader behavior in people management: Antecedents and consequences. Academy of Management Journal, 58(2): 538-566.

Peter Ping Li ( $\mathrm{PhD}$, George Washington University) is professor of international management at Xian Jiaotong-Liverpool University, China, and professor of Chinese business studies at Copenhagen Business School, Denmark. Before joining XJTLU and CBS, he was professor of management at California State University. His primary research focus is on building geocentric (West-meeting-East) theories from the cultural and historical perspectives. He is regarded as the global thought leader in the two fastest growing areas: (1) indigenous management research, and (2) emerging multinational firms. He has published about 50 articles in academic journals, 16 book chapters, and four books. He serves on the editorial boards of seven major management journals. He is the founding Editor-in-Chief of Journal of Trust Research as well as Senior Editor of Management and Organization Review and also former Senior Editor of Asia Pacific Journal of Management.

Tomoki Sekiguchi ( $\mathrm{PhD}$, University of Washington) is professor of management at the Graduate School of Economics, Osaka University. His research interests center around employee behaviors, organizational justice, person-environment fit, hiring decision making, management fashion, cross-cultural organizational behavior, and international human resource management. His work has been published in such journals as Personnel Psychology, Organizational Behavior and Human Decision Processes, Journal of World Business, Applied Psychology: An International Review, and International Journal of Human Resource Management. He currently serves as the associate editor for Applied Psychology: An International Review and served as guest editor for Asian Business \& Management. He is a member of the editorial boards of Cross Cultural \& Strategic Management, Australasian Journal of Organisational Psychology, Asia Pacific Management Review, and Japanese Journal of Administrative Science.

Kevin Zhou (PhD, Virginia Polytechnic Institute and State University) is the Chang-Jiang Scholar Chair Professor of strategy/international business at the School of Business, the University of Hong Kong. His research interests include strategic orientation and product innovation, trust and relational ties, and strategic issues in international business and emerging economies. Professor Zhou has published numerous papers in prestigious journals such as Administrative Science Quarterly, Strategic Management Journal, Journal of Marketing, Journal of International Business Studies, and Organization Science, among others. He currently serves as Senior Editor of Asia Pacific Journal of Management and editorial board member of Strategic Management Journal and Journal of International Business Studies. He is also the World's Top $1 \%$ cited scholars based on ISI's Essential Science Indicators (ESI) since 2011. 